\title{
The influence of mulberry leaf flavonoids and Candida tropicalis on antioxidant function and gastrointestinal development of preweaning calves challenged with Escherichia coli 0141:K99
}

\author{
B. Wang, ${ }^{1}$ C. T. Yang, ${ }^{1}$ Q. Y. Diao, and Y. Tu ${ }^{2}$ \\ Feed Research Institute, Chinese Academy of Agricultural Sciences, Beijing 100081, P. R. China
}

\begin{abstract}
This study investigated the effects of mulberry (Morus alba L.) leaf flavonoids and Candida tropicalis on the growth, gastrointestinal development, enzyme activity of gastrointestinal digesta, and blood antioxidant function of dairy calves challenged with Escherichia coli O141:K99. A total of 15 Holstein preweaning bull calves (age $=28 \mathrm{~d}$; body weight $=51 \pm 3.9 \mathrm{~kg}$, mean \pm standard deviation) were randomly divided into 3 homogeneous groups with no supplementation (control, CON), Candida tropicalis added at $1 \mathrm{~g} /$ calf per day $(\mathrm{CT})$, and mulberry leaf flavonoids added at 3 $\mathrm{g} /$ calf per day (MLF). The feed efficiency was greater in calves fed MLF than in CON either before or after the $E$. coli challenge test. The fecal score increased after $E$. coli challenge, but it was greater in the $\mathrm{CON}$ group than in the CT treatment and in the MLF group at d 1, 2, and 3 after the E. coli challenge. Calves fed the CT diet showed decreased blood $\beta$-hydroxybutyrate concentrations compared with those on the CON and MLF diets before the E. coli challenge. Dietary supplementation with $\mathrm{CT}$ resulted in lower blood superoxide dismutase activity than the CON after E. coli challenge. The calves fed CT and MLF showed much lower blood glutathione peroxidase activity than the CON group after being challenged with $E$. coli. The tunica mucosa of the duodenum was lower in CT and MLF than in CON. The lactase activity of the jejunal digesta was greater in MLF than in CON and CT. In summary, MLF and CT supplementation might effectively improve antioxidant function and reduce the incidence of oxidative stress after challenge with $E$. coli in 28 -dold preweaning calves, and this effect may be partially explained by the relative decreases in blood superoxide dismutase and glutathione peroxidase as well as fecal score.
\end{abstract}

Received October 7, 2017.

Accepted March 10, 2018.

${ }^{1}$ These 2 authors contributed equally to this work.

${ }^{2}$ Corresponding author: tuyan@caas.cn
Key words: antioxidant function, calf, gastrointestinal tract, morphology

\section{INTRODUCTION}

Weaning or dietary changes in neonatal animals can lead to oxidative stress due to an imbalance in free radical removal and production (Enríquez et al., 2011; Panda and Cherian, 2014). This imbalance could have many negative effects on animal health, such as lipid oxidation and subsequent metabolic disease, and could eventually reduce animal production (Enríquez et al., 2011; Panda and Cherian, 2014). Feed supplementation is a common practice in modern dairy farming to prevent oxidative stress and the resulting metabolic diseases in calves during preweaning and postweaning phases (Enríquez et al., 2011). The pursuit of "natural" feed additives has gained enormous popularity, particularly since antibiotic growth promoters were banned in the European Union.

Plant secondary metabolites, such as flavonoids and saponins, have anti-inflammatory, antioxidant, and antimicrobial properties in humans or ruminants (Harborne and Williams, 2000; Wang et al., 2017a) and mulberry could alleviate the severity of diarrhea in an experimental model of diarrhea in mice and rats (Di Carlo et al., 1993). Mulberry (Morus alba L.) leaves may be a potential source of natural antioxidants due to their marked antioxidant activity (ArabshahiDelouee and Urooj, 2007). Additionally, they have been reported to increase the ruminal utilization of fiber and promote lactation performance in ruminants (Venkatesh Kumar et al., 2015) mainly due to their flavonoid contents (Chon et al., 2009). Mulberry leaf flavonoids (MLF) have been shown to have antioxidative and anti-inflammatory properties (Chon et al., 2009) as well as to improve the digestibility of nutrients and reduce methane emission (Chen et al., 2016). Yeast has been found to be a good alternative to promote ruminant growth and improve gastrointestinal morphology (Xiao et al., 2016), but Candida tropicalis (CT) typically inhabits the bodies of animals (Yahashi et al., 
1996). However, compared with Saccharomyces cerevisiae, $\mathrm{CT}$ has excellent potential to degrade dietary fiber and activate fiber-decomposing bacteria, thereby increasing the VFA concentration and promoting DM digestibility by affecting the rumen microbiota (Marrero et al., 2015). Therefore, CT and MLF are potential alternatives as additives to improve rumen fermentation and digestion in preweaning calves, which are prone to health problems such as diarrhea (Enríquez et al., 2011). However, the protective roles of these additives in reducing gastrointestinal issues might differ, such as the antioxidative and anti-inflammatory properties of MLF (Chon et al., 2009) or the documented role of $\mathrm{CT}$ in regulating rumen fermentation (Marrero et al., 2015).

In our previous study, MLF and CT were found to increase nutrient digestibility, dietary $\mathrm{ME}$, and rumen fermentation in preweaning calves (Yang et al., 2016; Zhang et al., 2017a). However, their function and efficiency in preweaning calves with diarrhea or with a health challenge remain unknown and their individual functions may differ. Thus, we hypothesize that animal growth, gastrointestinal tract (GIT) development, and antioxidant function of calves with diarrhea or a health challenge may be improved by feeding MLF or CT. Therefore, our goal was to perform an animal feeding and slaughter study to determine the effect of MLF and CT supplementation on the growth, antioxidant status, and gastrointestinal morphology of dairy calves following a challenge with Escherichia coli O141:K99.

\section{MATERIALS AND METHODS}

\section{Candida Tropicalis and Mulberry Leaf Flavonoids}

The CT $\left(5.0 \times 10^{9} \mathrm{cfu} / \mathrm{g}\right.$, Beijing Huanong Biological Engineering Co. Ltd., Beijing, China) and MLF (5\%, Xi'an Feida Biotechnology Co. Ltd., Xi'an, China) were purchased commercially. The commercial MLF was a mixed extract of mulberry leaf that mainly consisted of flavones $(65.0 \%$, wt $/ \mathrm{wt})$, flavonols $(20.0 \%$, wt $/ \mathrm{wt})$, and other polyphenols $(15.0 \%$, wt/wt) that share a common flavan core (15 carbon atoms).

\section{Animals, Diets, and Experimental Design}

Fifteen clinically healthy Chinese Holstein bull calves (age $=28 \mathrm{~d} ; \mathrm{BW}=51 \pm 3.9 \mathrm{~kg}$ ) were selected and randomly assigned to 1 of 3 treatments with 5 calves in each group: no supplementation (control, CON), CT at $1 \mathrm{~g} /$ calf per day $(\mathrm{CT})$, and MLF at $3 \mathrm{~g} /$ calf per day (MLF). The CT and MLF supplementation dose was based on a previous study in our laboratory that showed an increased BW, when the MLF was used 2 $\mathrm{g} / \mathrm{d}$ per calf before weaning $(55 \mathrm{~d})$ and $4 \mathrm{~g} / \mathrm{d}$ per calf after weaning, as well as the CT was used $1 \mathrm{~g} / \mathrm{d}$ per calf (Zhang et al., 2017a). Calves were fed colostrum for 3 d after birth and then offered pasteurized whole milk twice daily until d 21 when they were subsequently fed milk replacer (MR). The study was initiated when calves were $28 \mathrm{~d}$ of age and completed when calves were $63 \mathrm{~d}$ of age. The experimental period included a 28-d feeding trial, a 7-d challenge period using E. coli, and finally on the last day of the study all calves were harvested (Figure 1). The calves were fed MR based on their BW (1.2\% BW/calf daily), and the CT and MLF were added to the MR emulsion, which was prepared by the method of Zhang et al. (2017b). Clean fresh water and dry pelleted starter were provided ad libitum. The dietary ingredients and nutrient composition of the starter and MR are presented in Table 1, and they were purchased from Beijing Precision Animal Nutrition Center (Beijing, China). Calves were fed twice daily at 0800 and $1600 \mathrm{~h}$, and they were housed in a naturally ventilated barn and kept in individual pens $(1.6 \mathrm{~m} \times$ $3.6 \mathrm{~m}$ ) bedded with wood shavings. The intake of starter and total DMI were measured daily, and BW was measured on d 28, 42, 56, and 63. During the morning feeding on d 56, E. coli $\left(10^{9} \mathrm{cfu} / \mathrm{mL}\right.$; no. CVCC 222 , serotype: O141:K99), which was proofed by the China Institute of Veterinary Drugs Control (Beijing, China), was mixed with MR and fed to the calves at $10 \mathrm{~mL}$ for each calf. The choice of E. coli O141:K99 was based on our previous study that found it could induce the calf diarrhea around $30 \mathrm{~d}$ after birth (Zhou et al., 2011). The animals selected for this study were provided by a commercial dairy farm (Sanyuan Co., Beijing, China) and the experimental procedures were approved by the Animal Ethics Committee of the Chinese Academy of Agricultural Sciences (Beijing, China).

\section{Sampling and Analysis}

Daily DMI was recorded throughout the trial. Samples of the starter feed and the orts were collected once daily to determine the DMI, and the feed intake was calculated based on the feed offered and the orts. The ADG was calculated based on the BW change divided by the days. Feed efficiency was calculated based on the ADG divided by the feed intake. The ingredients of the starter and the total mixed starter were dried in a forced-air oven at $65^{\circ} \mathrm{C}$ for $48 \mathrm{~h}$, then ground through a 2-mm screen (Wiley Laboratory Mill, Arthur H. Thomas Co., Philadelphia, PA) and through a 1-mm screen in a Cyclotec mill (Tecator 1093, Tecator AB, Höganäs, Sweden). Then, the DM $\left(105^{\circ} \mathrm{C}\right.$ for $\left.5 \mathrm{~h}\right), \mathrm{CP}$ (method 988.05; AOAC, 1990), ash (method 942.05; AOAC, 1990), and ether extract (method 920.39; 


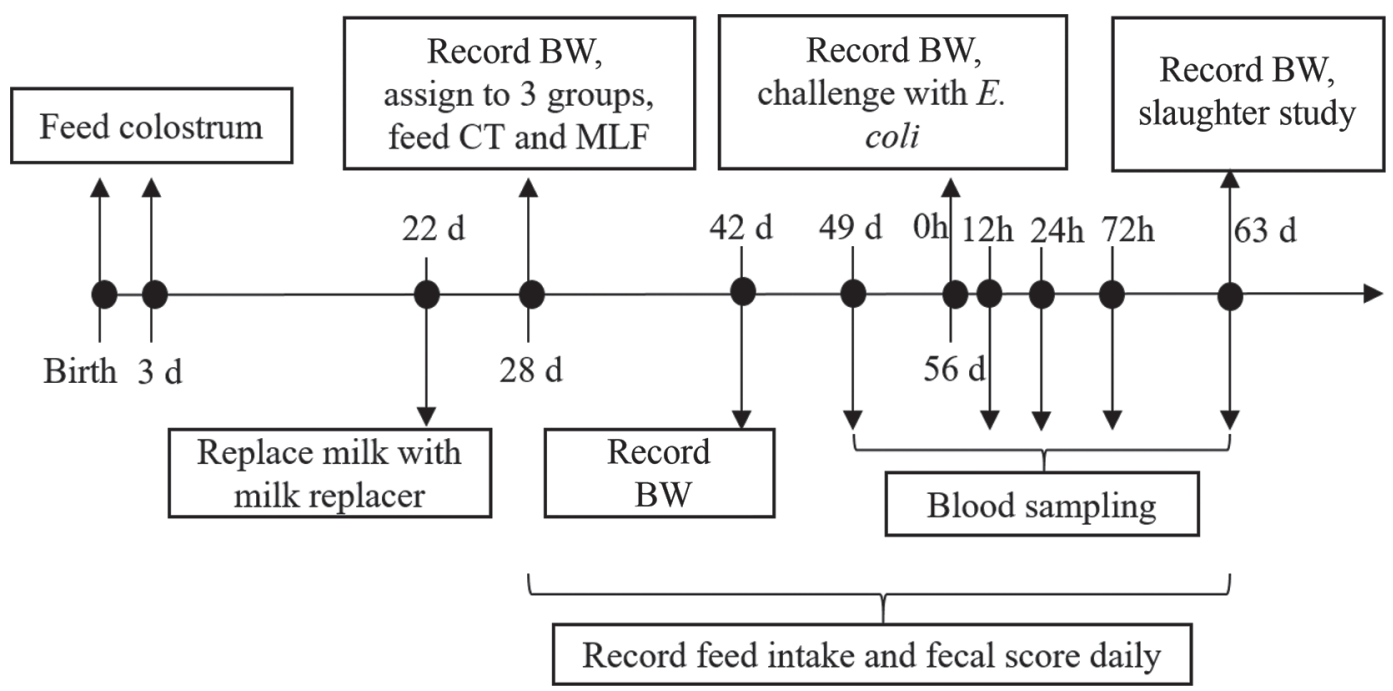

Figure 1. The timeline of experimental design of this study. Dietary supplementation with mulberry leaf flavonoids (MLF) and Candida tropicalis $(\mathrm{CT})$.

AOAC, 2000) contents were analyzed. The NDF and ADF contents were determined with an Ankom A200 apparatus (Ankom Technology, Macedon, NY) with heat-stable amylase (Ankom Technology) and sodium sulfite (Fisher Scientific, Waltham, MA) and expressed inclusive of residual ash (Van Soest et al., 1991).

The fecal score of the calves was determined every day before the morning milk feeding during the experiment according to the method described by Magalhães et al. (2008). Briefly, fecal score was recorded as 1 when firm, 2 when soft or of moderate consistency, 3 when runny or as mild diarrhea, and 4 when watery and profuse diarrhea. The potential diarrhea was defined when the fecal score was 2, and the diarrhea was defined when the fecal score was above 2 . At $0,12,24$, and $72 \mathrm{~h}$ after the calves were fed $E$. coli, the feces were collected according to the method by Ellinger et al. (1980).

On $\mathrm{d}-7$ and $0,12,24,72 \mathrm{~h}$, and $7 \mathrm{~d}$ after the $E$. coli challenge test, blood samples were collected into Li-heparin-containing vacutainer tubes (Becton, Dickinson and Company, Franklin Lakes, NJ) by jugular venipuncture, and the plasma was isolated by centrifugation at $3,000 \times g$ for $15 \mathrm{~min}$ at $4^{\circ} \mathrm{C}$. The samples were then stored at $-20^{\circ} \mathrm{C}$ to determine the biochemical variables using an Auto Analyzer 7020 (Hitachi High-Technologies Corporation, Tokyo, Japan) and commercial kits for each plasma biochemical parameter. Plasma parameters including BUN, total protein, glucose, BHB, aspartate aminotransferase, alanine aminotransferase, alkaline phosphatase (ALP), lactate dehydrogenase (LDH), and cortisol were analyzed using blood colorimetric commercial kits (DiaSys Diag- nostics Systems GmbH, Frankfurt, Germany). The concentrations of malondialdehyde (MDA), glutathione peroxidase (GSH-Px), superoxide dismutase (SOD), and IFN- $\gamma$ were determined with bovine ELISA kits

Table 1. Ingredients and nutrient composition (\% of DM unless specified otherwise) of the starter and milk replacer used in the experiment

\begin{tabular}{lcc}
\hline Item & Starter & Milk replacer $^{1}$ \\
\hline Ingredient & & \\
Corn & 20.0 & \\
Extruded corn & 22.9 & \\
Soybean meal & 20.0 & \\
Extruded soybean & 18.0 & \\
Dried whey & 5.00 & \\
Wheat bran & 10.0 & \\
CaHPO & & \\
Limestone & 0.80 & \\
NaCl & 1.80 & \\
Premix & 0.50 & \\
Nutrient level & 3 & \\
DM & 1.00 & \\
OM & 85.4 & 97.4 \\
CP & 92.2 & 94.9 \\
Ether extract & 19.1 & 24.3 \\
NDF & 2.21 & 12.9 \\
ADF & 18.6 & 4.02 \\
Ca & 10.7 & 2.11 \\
P & 1.09 & 1.07 \\
Gross energy, MJ/kg & 0.47 & 0.48 \\
\hline
\end{tabular}

${ }^{1}$ Provided by the Beijing Precision Animal Nutrition Research Center (Beijing, China).

${ }^{2}$ The premix provided the following per kilogram of starter: vitamin A, 15,000 IU; vitamin D, 5,000 IU; vitamin E, $50 \mathrm{mg}$; Fe, $90 \mathrm{mg} ; \mathrm{Cu}$ $12.5 \mathrm{mg}$; Mn, $30 \mathrm{mg}$; Zn, $90 \mathrm{mg}$; Se, $0.3 \mathrm{mg}$; I, $1.0 \mathrm{mg}$; and Co, $0.5 \mathrm{mg}$. ${ }^{3}$ Nutrient levels were measured values. 
(Nanjing Jiancheng Bioengineering Institute, Nanjing, Jiangsu, China).

\section{Gastrointestinal Morphology and Digesta Enzyme Activity}

Before the morning feeding on the last day of the experiment (d 63), all calves were slaughtered and GIT was exteriorized, the rumen, omasum, duodenum, and jejunum were tied off using cotton string, and separated after slaughter following a previously described method (Krueger et al., 2010). Homogenized digesta of the rumen and abomasum were separately collected from 15 calves and transferred into $50-\mathrm{mL}$ sterilized centrifuge tubes stored at $-80^{\circ} \mathrm{C}$. Each part of the GIT was weighted after the digesta was totally removed, and 2 replicate $1-\mathrm{cm}^{2}$ tissue samples were collected from the rumen, abomasum, duodenum, jejunum, and ileum and fixed in $10 \%$ neutral buffered formalin overnight. The samples were then dehydrated, cleared, and embedded in paraffin. The standard hematoxylin and eosin procedure was used for subsequent section analysis.

The ruminal and abomasal digesta samples were thawed at $4^{\circ} \mathrm{C}$, sonicated, and the supernatant was obtained by centrifugation at $20,000 \times g$ at $4^{\circ} \mathrm{C}$ for 15 min. The total protein concentration of the ruminal and abomasal digesta in the supernatant was determined according to the Hartree (1972). Enzyme activity, including that of carboxymethylcellulose, $\alpha$-amylase, xylanase, $\alpha$-glucosidase, $\beta$-glucosidase, and urease in the rumen digesta and protease and rennet in the abomasum digesta, as well as $\alpha$-amylase, lipase, tryptase, lactase, and chymotrypsin in duodenum, jejunum, and ileum digesta, were determined using bovine ELISA kits (Beijing Sino-UK Institute of Biological Technology, Beijing, China).

\section{Statistical Analysis}

Data from the calves before and after the E. coli challenge as well as the overall animal performance data and blood characteristics were analyzed as a randomized complete block design with repeated measures using PROC MIXED of SAS (version 9.2, SAS Institute Inc., Cary, NC). Time, treatment, and the treatment by time interaction were fixed effects, and the calves within each diet was a random effect. The effect of time was included as a repeated measure. For the repeated measures analysis, the covariance structure with the lowest Akaike information criterion was used. Variables in the slaughtered samples, including gastrointestinal digesta enzyme activity, GIT morphology, and GIT slaughter weight, were analyzed using PROC GLM of
SAS. The statistical model was the same as indicated above, but time and the treatment by time interaction were omitted. Least squares means were calculated and separated using the PDIFF option in SAS, and differences between diets were detected using Tukey's tests. Day-28 BW was used as a covariate in the statistical analysis. The results were reported as least squares means; significance was declared at $P \leq 0.05$, and a tendency was declared at $0.05<P<0.10$.

\section{RESULTS}

\section{Feed Intake and Animal Growth}

The ADG was greater in calves fed MLF than in CON $(P<0.01)$ and CT $(P=0.046)$ after E. coli challenge (Table 2). No differences were found in total DMI and starter DMI among the 3 dietary treatments either before or after the E. coli challenge test. Feed efficiency was greater in calves fed MLF than in CON both before $(P=0.03)$ and after $(P=0.04) E$. coli challenge. We observed a time effect in ADG, starter DMI, and total DMI before the challenge $(P<0.01)$.

\section{Fecal Score}

Time significantly affected fecal score with fecal score of calves challenged with $E$. coli (wk 5) increasing after the challenge in all 3 groups $(P<0.01$; Figure 2$)$. The fecal score in the CON group was greater than in the CT $(P<0.01)$ and MLF treatment $(P<0.01)$ at $\mathrm{d} 1$, 2 , and 3 after E. coli challenge (wk 5 ).

\section{Plasma Characteristics}

Table 3 presents the mean concentrations of total protein, BUN, glucose, BHB, aspartate aminotransferase, alanine aminotransferase, ALP, LDH, and cortisol, and the antioxidant and immune function parameters including SOD, MDA, GSH-Px, and IFN- $\gamma$. The diet supplemented with $\mathrm{CT}$ showed decreased BHB concentrations compared with the CON $(P=0.03)$ and MLF $(P=0.01)$ treatments before challenge with $E$. coli. Calves fed CT $(P<0.01)$ and MLF $(P<0.01)$ showed greater ALP activity compared with CON, and ALP activity was greater in CT than in $\operatorname{MLF}(P=0.02)$ before being challenged with $E$. coli, but no differences were found among the treatments after the challenge. Calves fed CT $(P=0.03)$ and MLF $(P=0.04)$ both showed lower blood LDH activity values compared with the CON treatment after challenge with E. coli. Dietary supplementation with $\mathrm{CT}$ resulted in lower blood SOD activity than the CON $(P=0.02)$ after challenge with 


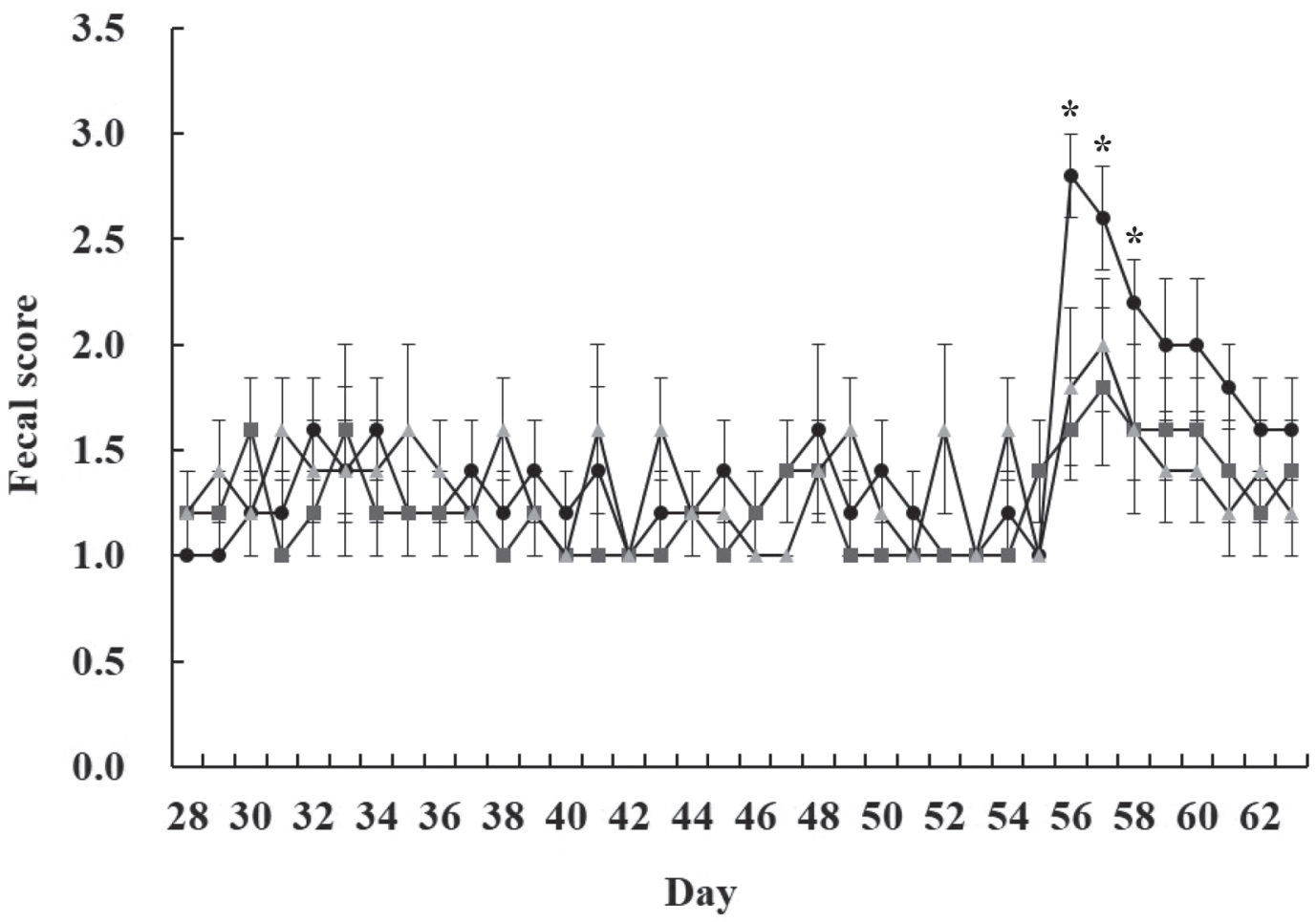

Figure 2. Change in the fecal score of calves fed TMR with no supplementation (control; --)- Candida tropicalis (CT) supplementation $(-\mathbf{-}-)$, and mulberry leaf flavonoid (MLF) supplementation (gray triangles) throughout the experiment. Bars indicate the SE. $*$ indicates that the fecal score was greater in the control than in the CT and MLF treatment $(P<0.05)$.

E. coli, but all 3 groups showed greater SOD activity after the challenge than before (Figure 3a; $P<0.01$ ). For blood GSH-Px activity, both the calves fed CT $(P$ $=0.04)$ and $\operatorname{MLF}(P=0.05)$ showed much lower values compared with the CON after being challenged with $E$. coli. The blood GSH-Px activity at $12 \mathrm{~h}$ was greater in CON than in MLF $(P=0.02)$ and was greater in CON than in either $\mathrm{CT}(P=0.01)$ and $\operatorname{MLF}(P=0.04)$ at 7 d after the $E$. coli challenge (Figure $3 \mathrm{~b}$ ).

\section{Slaughter Weight}

The BW $(76.6 \mathrm{~kg})$, and the weights of the stomach $(1,601 \mathrm{~g})$, small intestine $(2,094 \mathrm{~g})$, large intestine (726 $\mathrm{g})$, and the entire GIT $(4,446 \mathrm{~g})$ recorded on d $63 \mathrm{did}$ not differ among treatments (Table 4 ). In addition, the weights of the rumen, reticulorumen, omasum, small intestine, and large intestine as a percentage of BW were similar among the 3 treatments. The weights of

Table 2. Effect of dietary supplementation with mulberry leaf flavonoids (MLF) and Candida tropicalis (CT) on growth, starter DMI, and total DMI in calves before and after challenge with Escherichia coli

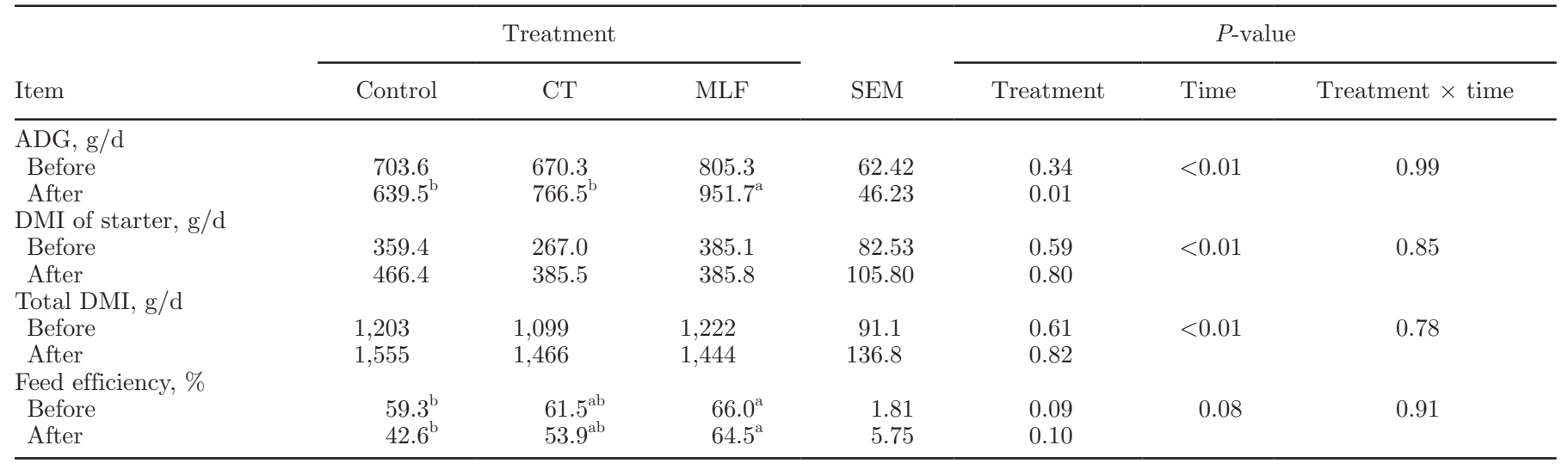

${ }_{\mathrm{a}, \mathrm{b}}$ Means within a row with different superscripts differ significantly $(P<0.05)$. 
Table 3. Effect of dietary supplementation with mulberry leaf flavonoids (MLF) and Candida tropicalis (CT) on plasma metabolic variables in calves before and after challenge with Escherichia coli

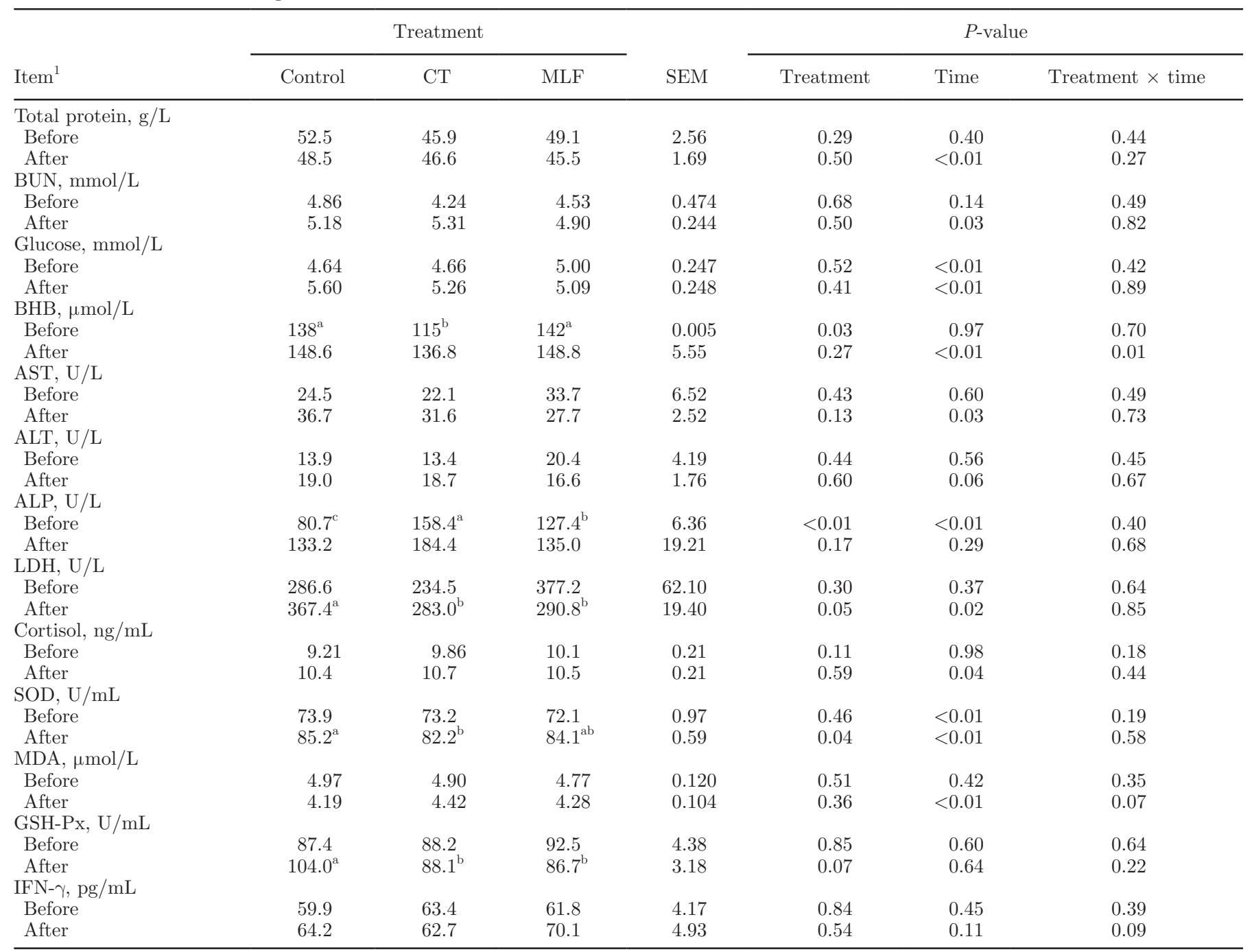

${ }^{\mathrm{a}-\mathrm{C}}$ Means within a row with different superscripts differ significantly $(P<0.05)$.

${ }^{1} \mathrm{ALT}=$ alanine aminotransferase $; \mathrm{AST}=$ aspartate aminotransferase ALP $=$ alkaline phosphatase LDH $=$ lactate dehydrogenase $;$ GSH-Px $=$ glutathione peroxidase; $\mathrm{MDA}=$ malondialdehyde; $\mathrm{SOD}=$ superoxide dismutase.

the abomasum as a percentage of BW were greater in $\mathrm{CT}(P<0.01)$ and $\operatorname{MLF}(P=0.03)$ than in CON.

\section{Morphology of Rumen, Abomasum, and Small Intestine}

The thickness of tunica mucosa of the abomasum was lower in MLF than in CON $(P=0.05$; Table 5$)$. The thickness of tunica mucosa of the duodenum was lower in CT $(P=0.03)$ and MLF $(P<0.01)$ than in CON. We observed no differences for other morphological variables of the rumen, abomasum, duodenum, jejunum, and ileum.

\section{Enzymatic Activities of Ruminal and Abomasal Digesta}

The enzymatic activities of the ruminal, abomasal, and small intestinal digesta in calves after challenge with $E$. coli are listed in Table 6 . The xylanase activity of the rumen digesta was greater for MLF than in CON $(P=0.05)$. Protease activity of the abomasal digesta was greater in MLF than in CON $(P=0.03)$ and CT $(P=0.03)$, but no difference was found between $\mathrm{CT}$ and CON. The lactase activity of the jejunal digesta was greater in MLF than in CON $(P<0.01)$ and CT $(P<0.01)$, but no difference was found between $\mathrm{CT}$ and CON. The chymotrypsin activity of the jejunal 
digesta was greater in $\mathrm{CON}$ than in $\mathrm{CT}(P=0.04)$ and MLF $(P=0.03)$, but no difference was found between $\mathrm{CT}$ and MLF. The other enzyme activities were similar among the 3 treatments.

\section{DISCUSSION}

Interest is increasing in the use of alternatives to antibiotics for the prevention and treatment of disease in calves (Casewell et al., 2003; Heinrichs et al., 2003). This study showed that MLF supplementation improved ADG and feed efficiency after calves were challenged with $E$. coli, but did not occur with CT,
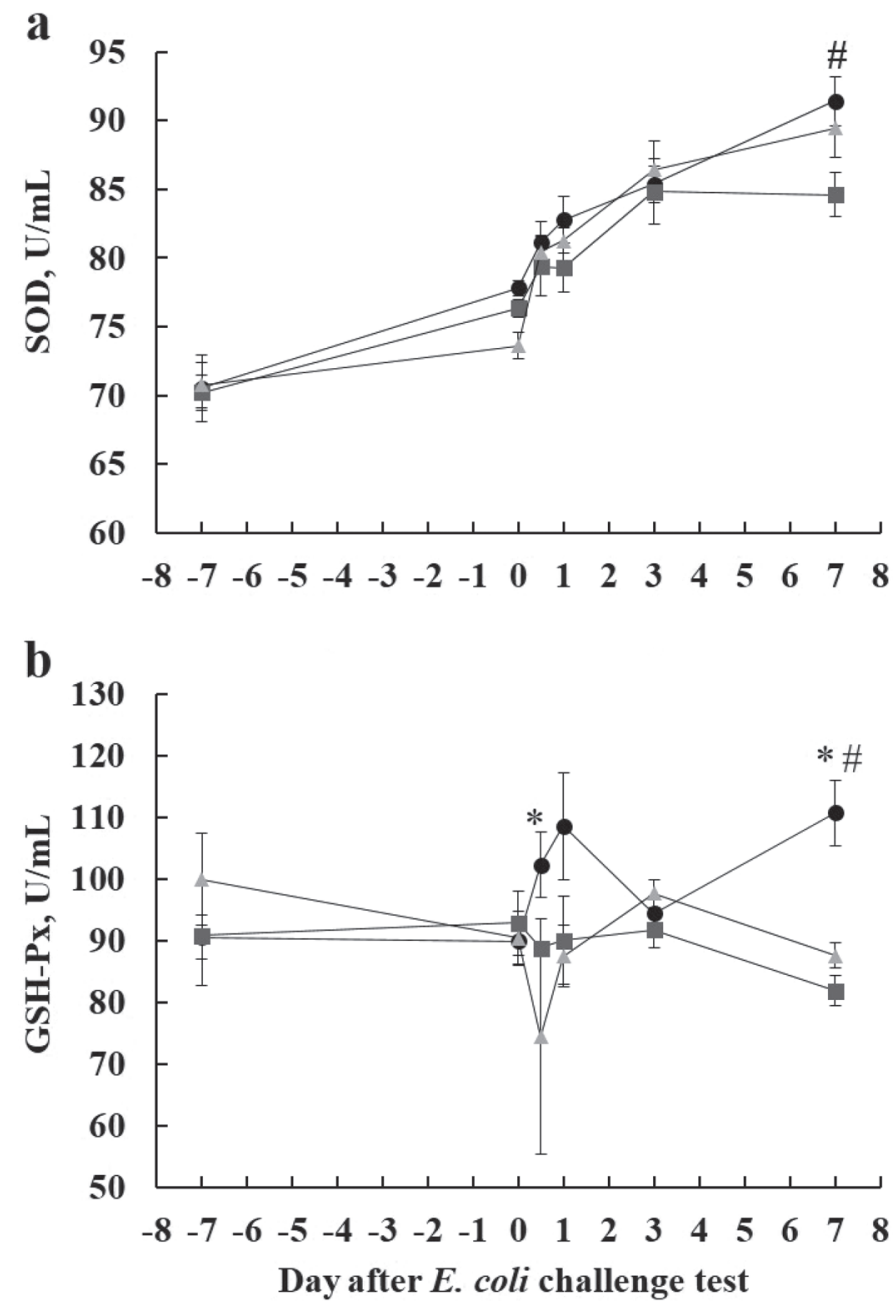

Figure 3. Change in superoxide dismutase (SOD; a) and glutathione peroxidase (GSH-Px; b) activities of calves fed TMR with no supplementation (control; -๑-), Candida tropicalis supplementation (CT; - - -), and mulberry leaf flavonoid supplementation (MLF; gray triangles) before and after challenge with Escherichia coli. Bars indicate the SE. \# indicates that the blood parameter activity was greater in the control than in the $\mathrm{CT}$ treatment $(P<0.05)$. ${ }^{*}$ indicates that the blood parameter activity was greater in the control than in the MLF $(P<0.05)$ treatments. which agrees with previous work (Bi et al., 2017). It was reported that enterotoxigenic E. coli O141:K99 is unlikely to cause diarrhea in calves older than 2 wk in natural conditions (Runnels et al., 1980). It is well known that the ability of enterotoxigenic E. coli K99 to bind to the small intestinal epithelium is age dependent and gradually decreases from $12 \mathrm{~h}$ of age to $2 \mathrm{wk}$ of age of calves (Runnels et al., 1980). Thus, diarrhea might not be achieved after calves were challenged with $E$. coli O141:K99 in the current study, even though the fecal score was increased (but no systemic changes such as dehydration, altered demeanor, or signs requiring medical intervention). In addition, the relative lower fecal score was found in the CT and MLF. Thus, we estimated the CT and MLF were good for digestive function in calves. However, we have to say there were limitations of this study section, as the results of the present study could not be extrapolated to cases of $E$. coli O141:K99 naturally induced diarrhea. More studies need to be done to indicate the effects of CT and MLF on naturally acquired diarrhea or in an experimental model of enterotoxigenic E. coli diarrhea in calves younger than $5 \mathrm{~d}$ of age.

\section{Animal Performance}

In the present study, we found that MLF had higher ADG and feed efficiency, and lower fecal scores compared with CON after E. coli K99 challenge. It was reported by other researchers that the supplementation with extract of plant flavonoids (Bioflavex) did not affect ADG, feed consumption, or feed conversion ratio (Balcells et al., 2012). The current findings using MLF were consistent with the results of a previous study that the calves under wk 5 to 6 fed higher dose of flavonoids $\left(3.6 \times 10^{-3} \mathrm{~g} / \mathrm{kg}\right.$ of BW $)$ had higher ADG than those fed no or lower dose of flavonoids (Yaghoubi et al., 2008). These results might indicate the effects of flavonoids on animal performance are dose dependent. Our previous study showed that diets supplemented with MLF and CT could be used to increase the BW of calves by increasing the apparent digestibility of the diet after $56 \mathrm{~d}$ of age (Zhang et al., 2017a). These results are supported by the increased ruminal xylanase, abomasal protease, and jejunal lactase activity in calves fed MLF in this study. It was reported that pancreatic amylase secretion is probably a limiting factor in the use of starch by young calf, as the starch is a major energy source in calf starters (Sissons, 1981). The proteases are secreted by the abomasum and pancreas, which can hydrolyze dietary protein into small peptides in cattle (Sissons, 1981). The current study on small intestinal enzyme activity confirmed previous findings that lactase activity was highest in the jejunum, 
Table 4. Effect of dietary supplementation with mulberry leaf flavonoids (MLF) and Candida tropicalis (CT) on the harvested weight of the gastrointestinal tract (GIT) of calves after challenge with Escherichia coli

\begin{tabular}{lcccrc}
\hline \multicolumn{3}{c}{ Treatment } & & \\
\cline { 2 - 4 } Item & Control & CT & MLF & SEM & $P$-value \\
\hline BW, kg & 77.1 & 74.5 & 78.3 & 2.44 & 0.56 \\
Whole GIT, g & 4,411 & 4,448 & 4,539 & 357.7 & 0.96 \\
Stomach & 1,588 & 1,652 & 1,564 & 161.0 & 0.93 \\
Small intestine & 2,098 & 1,927 & 2,256 & 189.8 & 0.50 \\
$\quad$ Large intestine & 736 & 712 & 729 & 52.0 & 0.95 \\
Proportion of BW, & & & & & \\
Whole GIT & 5.68 & 5.69 & 5.81 & 0.370 & 0.96 \\
Stomach & 2.04 & 2.11 & 2.00 & 0.171 & 0.90 \\
$\quad$ Rumen & 1.12 & 1.15 & 1.07 & 0.125 & 0.90 \\
$\quad$ Reticulorumen & 0.25 & 0.22 & 0.21 & 0.026 & 0.58 \\
Omasum & 0.20 & 0.22 & 0.21 & 0.027 & 0.92 \\
$\quad$ Abomasum & $0.47^{\mathrm{b}}$ & $0.52^{\mathrm{a}}$ & $0.50^{\mathrm{a}}$ & 0.009 & 0.01 \\
Small intestine & 2.70 & 2.68 & 2.88 & 0.208 & 0.75 \\
Large intestine & 0.94 & 0.90 & 0.93 & 0.057 & 0.87 \\
\hline
\end{tabular}

${ }^{\mathrm{a}, \mathrm{b}}$ Means within a row with different superscripts differ significantly $(P<0.05)$.

somewhat lower in the duodenum, and much lower in the ileum (Coombe and Siddons, 1973). In addition, the increased amylase, protease, and lactase activity in calves fed MLF indicated its roles in improving the digestion of protein and starch of preweaned calves. The increased starch and protein digestive enzymes might result in increased digestibility, which was confirmed by the previous study (Zhang et al., 2017a). Then, the increased gastrointestinal digestive enzyme as well as the potential increased digestibility could explain the increased feeding efficiency and ADG in calves fed MLF compared with CON after being challenged with E. coli. Few studies have focused on the effects of CT on calf performance; the results of $\mathrm{CT}$ in calves from our

Table 5. Effect of dietary supplementation with mulberry leaf flavonoids (MLF) and Candida tropicalis (CT) on the morphology of the forestomach and small intestine of calves after challenge with Escherichia coli

\begin{tabular}{lccccc}
\hline & \multicolumn{3}{c}{ Treatment $^{1}$} \\
\cline { 2 - 3 } Item, ${ }^{1} \mu \mathrm{m}$ & Control & CT & MLF & SEM & P-value \\
\cline { 2 - 3 } Rumen & & & & \\
Papillae length & 2,097 & 2,045 & 2,047 & 374.7 & 0.99 \\
Papillae width & 721 & 633 & 688 & 109.3 & 0.85 \\
Tunica muscularis & 2,031 & 2,241 & 1,755 & 190.8 & 0.25 \\
Abomasum & & & & \\
Tunica mucosa & $489^{\mathrm{a}}$ & $465^{\mathrm{ab}}$ & $440^{\mathrm{b}}$ & 12.1 & 0.11 \\
Tunica muscularis & 1,988 & 3,071 & 2,731 & 312.6 & 0.16 \\
Duodenum & & & & 0.33 \\
Villus height & 433 & 330 & 332 & 46.5 & 0.32 \\
Crypt depth & 164 & 155 & 131 & 14.3 & 0.02 \\
Tunica mucosa & $819^{\mathrm{a}}$ & $737^{\mathrm{b}}$ & $695^{\mathrm{b}}$ & 17.7 & 0.60 \\
Tunica muscularis & 802 & 803 & 859 & 46.5 & 0.70 \\
V/C & 2.59 & 2.11 & 2.51 & 0.452 & 0.32 \\
Jejunum & 364 & 404 & 322 & 36.7 & 0.21 \\
Villus height & 143 & 129 & 116 & 8.8 & 0.35 \\
Crypt depth & 726 & 833 & 738 & 53.2 & 0.61 \\
Tunica mucosa & 465 & 518 & 536 & 48.6 & 0.63 \\
Tunica muscularis & 2.62 & 3.12 & 2.88 & 0.398 & \\
V/C & & & & & \\
Ileum & 399 & 389 & 381 & 47.6 & 0.95 \\
Villus height & 125 & 119 & 120 & 5.0 & 0.67 \\
Crypt depth & 752 & 789 & 696 & 73.5 & 0.63 \\
Tunica mucosa & 780 & 505 & 729 & 114.0 & 0.27 \\
Tunica muscularis & 3.27 & 3.25 & 3.24 & 0.321 & 1.00 \\
V/C & & & & \\
\hline
\end{tabular}

${ }_{\mathrm{a}, \mathrm{b}}$ Means within a row with different superscripts differ significantly $(P<0.05)$.

${ }^{1} \mathrm{~V} / \mathrm{C}=$ villus height/crypt depth. 
previous study showed increased BW on d 56 but not for other time points such as d 21, 28, and 42 preweaning and d 80 postweaning (Zhang et al., 2017a). Thus, more research on $\mathrm{CT}$ is needed in preweaned calves.

\section{Blood}

Several endogenous antioxidant enzymes, such as SOD and GSH-Px, exert antioxidant effects by converting oxygen-derived free radicals into less dangerous forms (Halliwell and Chirico, 1993). The activity of SOD and GSH-Px are induced by oxidative stress and these activity levels have been used to quantify oxidative stress in cells; the greater levels of these enzymes indicate more severe oxidative stress (van der Oost et al., 2003). Thus, the increased values of blood SOD and GSH-Px, as well as decreased MDA after calves were challenged with $E$. coli, indicated the oxidative stress occurred. The lower activities of blood SOD and GSH-Px indicated the relative lower oxidative stress of calves fed with MLF ad CT after E. coli challenge. Flavonoid supplementation has been found to increase antioxidant capacity, improve nonspecific immunity, and reduce oxidative stress by increasing SOD and GSH-
Px activity while decreasing the MDA concentration (Kahkonen et al., 1999). The underlying mechanism is that flavonoids act as a reducing agent and a hydrogen donor to neutralize oxygen free radicals and remove hydrogen peroxide and superoxide ions (Kahkonen et al., 1999). Saccharomyces cerevisiae fermentation products have also been reported to reduce diarrhea in calves (Alugongo et al., 2017), indicating the potential antioxidant function of yeast fermentation products in calves. However, no previous research has been conducted to determine the antioxidant function of $\mathrm{CT}$ in calves. Thus, the results from the present study indicate that CT may benefit preweaning calves, but more research is needed to clarify this.

\section{Morphology}

A greater proportion of the abomasum in $\mathrm{BW}$ in MLF and CT groups was found in the present study. It has been reported that the abomasum was the main digestion and absorption site in the preweaned period of calves (Meale et al., 2017). Increased mucosa permeability during nutrient absorption across the intestinal epithelium provides an important role in absorbing

Table 6. Effect of dietary supplementation with mulberry leaf flavonoids (MLF) and Candida tropicalis (CT) on the enzymatic activities of ruminal and abomasal digesta (per gram of true protein) in calves after challenge with Escherichia coli

\begin{tabular}{|c|c|c|c|c|c|}
\hline \multirow[b]{2}{*}{ Item $^{1}$} & \multicolumn{3}{|c|}{ Treatment } & \multirow[b]{2}{*}{ SEM } & \multirow[b]{2}{*}{$P$-value } \\
\hline & Control & $\mathrm{CT}$ & MLF & & \\
\hline \multicolumn{6}{|l|}{ Rumen } \\
\hline CMCase, U/g & 3.48 & 3.58 & 3.78 & 0.15 & 0.42 \\
\hline$\alpha$-Amylase, $\mathrm{U} / \mathrm{g}$ & $95.7^{\mathrm{b}}$ & $113.2^{\mathrm{ab}}$ & $153.9^{\mathrm{a}}$ & 17.45 & 0.12 \\
\hline Xylanase, U/g & 19.1 & 26.6 & 27.7 & 2.67 & 0.11 \\
\hline$\alpha$-Glucosidase, $\mathrm{U} / \mathrm{g}$ & 0.50 & 0.49 & 0.45 & 0.05 & 0.80 \\
\hline$\beta$-Glucosidase, U/g & 22.9 & 20.0 & 20.4 & 1.82 & 0.53 \\
\hline \multicolumn{6}{|l|}{ Abomasum } \\
\hline Protease, U/g & $19.1^{\mathrm{b}}$ & $19.1^{\mathrm{b}}$ & $26.7^{\mathrm{a}}$ & 2.00 & 0.05 \\
\hline Chymosin, U/g & 19.4 & 18.9 & 21.1 & 3.00 & 0.86 \\
\hline \multicolumn{6}{|l|}{ Duodenum } \\
\hline$\alpha$-Amylase, U/g & 230 & 119 & 106 & 47.3 & 0.20 \\
\hline Lipase, U/g & 37.9 & 35.9 & 42.7 & 2.84 & 0.28 \\
\hline Tryptase, U/mg & 3.01 & 2.97 & 3.01 & 0.055 & 0.83 \\
\hline Lactase, $\mathrm{U} / \mathrm{mg}$ & 38.3 & 35.5 & 41.7 & 2.41 & 0.26 \\
\hline Chymotrypsin, U/mg & 6.13 & 6.65 & 6.59 & 0.297 & 0.45 \\
\hline \multicolumn{6}{|l|}{ Jejunum } \\
\hline$\alpha$-Amylase, $\mathrm{U} / \mathrm{g}$ & 86.4 & 83.0 & 100.8 & 24.3 & 0.86 \\
\hline Lipase, U/g & 57.1 & 54.6 & 65.2 & 9.52 & 0.72 \\
\hline Tryptase, U/mg & 11.5 & 11.7 & 12.3 & 0.34 & 0.32 \\
\hline Lactase, $\mathrm{U} / \mathrm{mg}$ & $43.3^{\mathrm{b}}$ & $43.6^{\mathrm{b}}$ & $75.9^{\mathrm{a}}$ & 2.86 & $<0.01$ \\
\hline Chymotrypsin, U/mg & $24.3^{\mathrm{a}}$ & $20.5^{\mathrm{b}}$ & $19.2^{\mathrm{b}}$ & 1.08 & 0.03 \\
\hline \multicolumn{6}{|l|}{ Ileum } \\
\hline$\alpha$-Amylase, $\mathrm{U} / \mathrm{g}$ & 127.9 & 90.9 & 192.6 & 40.65 & 0.27 \\
\hline Lipase, U/g & 33.2 & 34.6 & 32.3 & 1.79 & 0.67 \\
\hline Tryptase, U/mg & 4.80 & 4.93 & 4.93 & 0.071 & 0.37 \\
\hline Lactase, $\mathrm{U} / \mathrm{mg}$ & 27.6 & 26.7 & 27.5 & 2.47 & 0.96 \\
\hline Chymotrypsin, U/mg & 11.3 & 11.2 & 11.3 & 0.88 & 0.99 \\
\hline
\end{tabular}

$\overline{\mathrm{a}, \mathrm{b}}$ Means within a row with different superscripts differ significantly $(P<0.05)$.

${ }^{1} \mathrm{CMCase}=$ carboxymethyl cellulose. 
nutrients (Ballard et al., 1995). However, the mucosa also serves an important role as a barrier against toxins and bacteria (Turner, 2009). It has also been reported that the flavonoid aglycones might bind to mucin via noncovalent interactions, which would protect the mucus layer and acts as a selective barrier during digestion and absorption (Gonzales et al., 2016). Thus, the lower mucosal thickness in the abomasum and duodenum in calves fed MLF might result in the greater absorption of nutrients rather than the toxins absorption, potentially altering blood characteristics, fecal score, and animal performance. The rumen epithelium consists of countless papillae, which are major absorptive structures critical for nutrient utilization (Graham and Simmons, 2005). Previous studies have found gastrointestinal morphology to be sensitive to physical or chemical changes in the diet, even in adult lactating dairy cows (Wang et al., 2017b). The effects of Saccharomyces cerevisiae fermentation products on ruminal morphology have been reported previously and were shown to enhance papillae length and papillae width (Lesmeister et al., 2004). Recently, Saccharomyces cerevisiae fermentation products were reported to improve gastrointestinal morphology, possibly due to increased butyrate concentration and increased Butyrivibrio and decreased Prevotella richness in the rumen fluid (Xiao et al., 2016), which might indicate an important role of rumen microbes and VFA. However, CT and MLF supplementation had no significant effects on rumen morphology in the present study, possibly due to the weak influence on the microbial activity or diversity in the rumen. In addition, the rumen was still under development, which might result in the supplementation of CT and MLF bypassing the rumen quickly (Baldwin et al., 2004). Thus, the main effects of CT and MLF might occur in the abomasum and small intestine in preweaning calves.

The current study has several limitations. The number of animals should be greater in future studies. The roles of CT and MLF as antioxidants should be evaluated by more feeding studies or cellular trials. In addition, more studies should be conducted to reveal the mechanism of CT and MLF and their effects on diarrhea by in vitro cell culture or omics techniques.

\section{CONCLUSIONS}

This study showed that MLF supplementation of the diets for preweaning calves improved animal ADG and feed efficiency but not CT. Supplementation of CT and MLF might reduce oxidative stress in $28 \mathrm{~d}$ old calves challenged with $E$. coli by decreasing blood SOD and GSH-Px activity and the fecal score. Overall, MLF and CT supplementation is potentially beneficial for the health of calves, but more research is needed to clarify the mechanism of their effects in the abomasum and small intestine for pre-weaned calves.

\section{ACKNOWLEDGMENTS}

This research was supported by grants from the Earmarked Fund for the Beijing Dairy Industry Innovation Consortium of the Agriculture Research System (BAIC06-2016, China) and the National Key Technology R\&D Program (2012BAD12B06, China). The authors thank the members of the Beijing Key Laboratory for Dairy Cow Nutrition, Feed Research Institute, Chinese Academy of Agricultural Sciences (Beijing, China) for their assistance with sampling and analysis. Special thanks go to Geoffrey Zanton from the US Dairy Forage Research Center (Madison, WI) for providing help with manuscript language revision.

\section{REFERENCES}

Alugongo, G. M., J. X. Xiao, Y. H. Chung, S. Z. Dong, S. L. Li, I. Yoon, Z. H. Wu, and Z. J. Cao. 2017. Effects of Saccharomyces cerevisiae fermentation products on dairy calves: Performance and health. J. Dairy Sci. 100:1189-1199.

AOAC (Association of Official Analytical Chemists). 1990. Official Methods of Analysis. 15th ed. AOAC, Arlington, VA.

AOAC (Association of Official Analytical Chemists). 2000. Official Methods of Analysis. 17th ed. AOAC International, Arlington, VA.

Arabshahidelouee, S., and A. Urooj. 2007. Antioxidant properties of various solvent extracts of mulberry (Morus indica L.) leaves. Food Chem. 102:1233-1240.

Balcells, J., A. Aris, A. Serrano, A. R. Seradj, J. Crespo, and M. Devant. 2012. Effects of an extract of plant flavonoids (Bioflavex) on rumen fermentation and performance in heifers fed high-concentrate diets. J. Anim. Sci. 90:4975-4984.

Baldwin, R., K. McLeod, J. Klotz, and R. Heitmann. 2004. Rumen development, intestinal growth and hepatic metabolism in the preand postweaning ruminant. J. Dairy Sci. 87:E55-E65.

Ballard, S. T., J. H. Hunter, and A. E. Taylor. 1995. Regulation of tight-junction permeability during nutrient absorption across the intestinal epithelium. Annu. Rev. Nutr. 15:35-55.

Bi, Y., C. Yang, Q. Diao, and Y. Tu. 2017. Effects of dietary supplementation with two alternatives to antibiotics on intestinal microbiota of preweaned calves challenged with Escherichia coli K99. Sci. Rep. 7:5439.

Casewell, M., C. Friis, E. Marco, P. McMullin, and I. Phillips. 2003. The European ban on growth-promoting antibiotics and emerging consequences for human and animal health. J. Antimicrob. Chemother. 52:159-161.

Chen, D., X. Chen, Y. Tu, B. Wang, C. Lou, T. Ma, and Q. Diao. 2016. Effects of mulberry leaf flavonoid and resveratrol on methane emission and nutrient digestion in sheep. Anim. Nutr. 1:362-367.

Chon, S. U., Y. M. Kim, Y. J. Park, B. G. Heo, Y. S. Park, and S. Gorinstein. 2009. Antioxidant and antiproliferative effects of methanol extracts from raw and fermented parts of mulberry plant (Morus alba L.). Eur. Food Res. Technol. 230:231-237.

Coombe, N. B., and R. C. Siddons. 1973. Carbohydrases of the bovine small intestine. Br. J. Nutr. 30:269-276.

Di Carlo, G., G. Autore, A. A. Izzo, P. Maiolino, N. Mascolo, P. Viola, M. V. Diurno, and F. Capasso. 1993. Inhibition of intestinal motility and secretion by flavonoids in mice and rats: Structure-activity relationships. J. Pharm. Pharmacol. 45:1054-1059. 
Ellinger, D. K., L. D. Muller, and P. J. Glantz. 1980. Influence of feeding fermented colostrum and Lactobacillus acidophilus on fecal flora of dairy calves. J. Dairy Sci. 63:478-482.

Enríquez, D., M. J. Hötzel, and R. Ungerfeld. 2011. Minimising the stress of weaning of beef calves: A review. Acta Vet. Scand. 53:28.

Gonzales, G. B., J. V. Camp, G. Smagghe, K. Raes, and A. Mackie. 2016. Flavonoid - gastrointestinal mucus interaction and its potential role in regulating flavonoid bioavailability and mucosal biophysical properties. Food Res. Int. 88:342-347.

Graham, C., and N. L. Simmons. 2005. Functional organization of the bovine rumen epithelium. Am. J. Physiol. Reg. Integr. Comp. Physiol. 288:R173-R181.

Halliwell, B., and S. Chirico. 1993. Lipid peroxidation: Its mechanism, measurement, and significance. Am. J. Clin. Nutr. 57(Suppl):715S$724 \mathrm{~S}$.

Harborne, J. B., and C. A. Williams. 2000. Advances in flavonoid research since 1992. Phytochemistry 55:481-504.

Hartree, E. F. 1972. Determination of protein: A modification of the Lowry method that gives a linear photometric response. Anal. Biochem. 48:422-427.

Heinrichs, A. J., C. M. Jones, and B. S. Heinrichs. 2003. Effects of mannan oligosaccharide or antibiotics in neonatal diets on health and growth of dairy calves. J. Dairy Sci. 86:4064-4069.

Kahkonen, M. P., A. I. Hopia, H. J. Vuorela, J. P. Rauha, K. Pihlaja, T. S. Kujala, and M. Heinonen. 1999. Antioxidant activity of plant extracts containing phenolic compounds. J. Agric. Food Chem. 47:3954-3962.

Krueger, W. K., H. Gutierrezbañuelos, G. E. Carstens, B. R. Min, W. E. Pinchak, R. R. Gomez, R. C. Anderson, N. A. Krueger, and T. D. A. Forbes. 2010. Effects of dietary tannin source on performance, feed efficiency, ruminal fermentation, and carcass and non-carcass traits in steers fed a high-grain diet. Anim. Feed Sci. Technol. 159:1-9.

Lesmeister, K. E., A. J. Heinrichs, and M. T. Gabler. 2004. Effects of supplemental yeast (Saccharomyces cerevisiae) culture on rumen development, growth characteristics, and blood parameters in neonatal dairy calves. J. Dairy Sci. 87:1832-1839.

Magalhães, V. J., F. Susca, F. S. Lima, A. F. Branco, I. Yoon, and J. E. Santos. 2008. Effect of feeding yeast culture on performance, health, and immunocompetence of dairy calves. J. Dairy Sci 91:1497-1509.

Marrero, Y., Y. Castillo, O. Ruiz, E. Burrola, and C. Angulo. 2015. Feeding of yeast (Candida spp.) improves in vitro ruminal fermentation of fibrous substrates. J. Integr. Agric. 14:514-519.

Meale, S. J., F. Chaucheyras-Durand, H. Berends, L. L. Guan, and M. A. Steele. 2017. From pre- to postweaning: Transformation of the young calf's gastrointestinal tract. J. Dairy Sci. 100:5984-5995.

Panda, A. K., and G. Cherian. 2014. Role of vitamin E in counteracting oxidative stress in poultry. J. Poult. Sci. 51:109-117.

Runnels, P. L., H. W. Moon, and R. A. Schneider. 1980. Development of resistance with host age to adhesion of K99+ Escherichia coli to isolated intestinal epithelial cells. Infect. Immun. 28:298-300.
Sissons, J. W. 1981. Digestive enzymes of cattle. J. Sci. Food Agric $32: 105-114$.

Turner, J. R. 2009. Intestinal mucosal barrier function in health and disease. Nat. Rev. Immunol. 9:799-809.

van der Oost, R., J. Beyer, and N. P. Vermeulen. 2003. Fish bioaccumulation and biomarkers in environmental risk assessment: a review. Environ. Toxicol. Pharmacol. 13:57-149.

Van Soest, P. J., J. B. Robertson, and B. A. Lewis. 1991. Methods for dietary fiber, neutral detergent fiber, and nonstarch polysaccharides in relation to animal nutrition. J. Dairy Sci. 74:3583-3597.

Venkatesh Kumar, R., C. Gautam, N. Shobha, and R. L. Shankar. 2015. Use of mulberry leaves as supplementary food in cow and goat to improve milk production. IJAR 1:81-84

Wang, B., Y. Tu, S. P. Zhao, Y. H. Hao, J. X. Liu, F. H. Liu, B. H. Xiong, and L. S. Jiang. 2017a. Effect of tea saponins on milk performance, milk fatty acids, and immune function in dairy cow. J. Dairy Sci. 100:8043-8052.

Wang, B., D. Wang, X. Wu, C. Jie, L. Mei, X. Huang, J. Wu, J. Liu, and L. Guan. 2017b. Effects of dietary physical or nutritional factors on morphology of rumen papillae and transcriptome changes in lactating dairy cows based on three different forage-based diets. BMC Genomics 18:353.

Xiao, J. X., G. M. Alugongo, R. Chung, S. Z. Dong, S. L. Li, I. Yoon, Z. H. Wu, and Z. J. Cao. 2016. Effects of Saccharomyces cerevisiae fermentation products on dairy calves: Ruminal fermentation, gastrointestinal morphology, and microbial community. J. Dairy Sci 99:5401-5412.

Yaghoubi, S. M. J., G. R. Ghorbani, H. R. Rahmani, and A. Nikkhah. 2008. Growth, weaning performance and blood indicators of humoral immunity in Holstein calves fed supplemental flavonoids. J. Anim. Physiol. Anim. Nutr. (Berl.) 92:456-462.

Yahashi, Y., H. Horitsu, K. Kawai, T. Suzuki, and K. Takamizawa. 1996. Production of xylitol from D-xylose by Candida tropicalis: The effect of D-glucose feeding. J. Ferment. Technol. 81:148-152.

Yang, C. T., Q. Y. Diao, P. B. Qu, B. W. Si, J. N. Ma, Y. C. Zhou, and Y. Tu. 2016. Effects of Candida tropicalis and mulberry leaf flavonoids on nutrient metabolism and rumen fermentation of calves. Chinese J. Anim. Nutr. 28:224-234. (In Chinese).

Zhang, L. Y., P. B. Qu, Y. Tu, C. T. Yang, and Q. Y. Diao. 2017a. Effects of flavonoids from mulberry leaves and candida tropicalis on performance and nutrient digestibility in calves. Kafkas Univ. Vet. Fak. Derg. 23:473-479

Zhang, R., Q. Y. Diao, Y. Zhou, Q. Yun, K. D. Deng, D. Qi, and Y. Tu. 2017b. Decreasing the $\mathrm{pH}$ of milk replacer containing soy flour affects nutrient digestibility, digesta $\mathrm{pH}$, and gastrointestinal development of preweaned calves. J. Dairy Sci. 100:236-243.

Zhou, Y., Q. Y. Diao, Y. Tu, and Q. Yun. 2011. Effects of yeast $\beta$-glucan and bacitrac in zinc on growth performance and gastrointestinal development of early-weaned calves. Chinese J. Anim. Nutr. 23:813-820. (In Chinese). 